\title{
Research on the Development of Pension Service Facilities
}

\author{
Hua Liu ${ }^{a}$ and Yonghui Liu ${ }^{b}$ \\ Xi'an University of Architecture and Technology, Xi'an 710055, China \\ ahxjd@foxmail.com,b1753911768@qq.com
}

Keywords: Aging, Pension Facilities, Service System.

\begin{abstract}
A service system of pension service facilities construction and development system is established, this system contains a number of subsystems, such as financing service system, design service system, operation service system, policies and regulations, administrative supervision system, and so on. Several suggestions are proposed, such as improve policies and regulations, increase financial support, focusing on professional training, improve the supervision mechanism, etc. The results will help to develop our elderly housing construction services.
\end{abstract}

\section{Introduction}

Our society is rapidly aging. Statistics show that as of 2015, the population of above 60 years old has reached 212 million, accounting for $15.5 \%$ of the total population; the population of above 65 years old has reached 137 million, accounting for $10.1 \%$ of the total population; In 2025 , the elderly population will maintain an average annual growth of 1 million; by 2050, the population of 60 years old and above will reach 400 million, almost one of four people will be elderly ${ }^{[1]}$. Visible, the living needs of the elderly will rise rapidly, the demand of develop and improve the pension service facilities is urgent.

\section{Present situation of pension facilities construction}

Since the introduction of the old building design code in 1999, it has made some progress. But there are still many problems.

\subsection{Lack of Depth of Policy and Regulations}

At present, our country has introduced a wide range of legal policies related to pension, but lack of depth. Although the country and some provinces and cities have introduced a number of policies and regulations, but the applicability of specific projects is poor, lack of maneuverability.

\subsection{Standard Specification is not specific}

In the current standard, there is a lack of the general design of the old residential buildings and the contents of the design of the large retirement community. Only one of the old building design specification for the design of the old residential design is too general, unable to meet the requirements of the design of diverse residential buildings ${ }^{[2]}$.

\subsection{Lack of Financial Support}

Pension community developers are facing financing difficulties. The amount of pension investment projects, long cycle, the pension project enterprises is difficult to obtain bank loans and stock market financing, and the financing cost is too high, the investment fund has just started and is not mature, causing the difficult financing situation ${ }^{[3]}$.

\section{Experience of developed countries}

Europe, the United States, Japan and other developed countries, the development of the elderly living facilities cannot be separated from the encourage and support of the policy. Under the support of the policy and law, the perfect welfare security system ensures the old age pension demand. At the same time, these countries have detailed pension facilities design standards to guide the construction of pension facilities. And, thanks to the developed financial markets, pension community developers can 
finance through multi-channel financing, to find its matching financial products.

\section{The construction of pension facilities development system}

Learn from the experience of developed countries, in view of the problems existing in the process of the construction of pension facilities, considering the various subjects involved in the construction, the system of pension facilities development is established.

\subsection{Financing Service System}

The main body of financing service system is government and financing institution. In the transformation of aging, the government should increase the financial support for the transformation, the establishment of special funds for the transformation of residential aging. In the development of the pension community, the bank loan is the main channel for developers financing, banks should provide more appropriate financing products to help developers solve the financing problem.

\subsection{Design Service System}

The design service main body is the design unit, is responsible for the aging transformation plan design and the retirement facility plan design. In the design of the aging transformation plan, the design unit should be based on the transformation of the applicant's physical condition, economic status and the rationality of the design. In the design of pension facilities, the design unit should be based on the relevant laws and regulations, design specifications and the needs of the elderly.

\subsection{Operational Service System}

The main body of the operation service system is the professional operation organization. The operation mechanism is similar to the professional hotel management company, has a professional management and technical personnel and a large number of professional nursing staff, they are responsible for the maintenance and operation of pension service facilities after the completion of the project, and to provide pension services, health care, living nursing related. In addition, they should also be used to statistics the use of facilities, the use of poor facilities to the research and development institutions to provide feedback.

\subsection{Policy and Regulation System}

The main body of policy and regulation system is all levels of government. The government through the formulation of laws and regulations, to provide protection for the construction and development of pension facilities. The participants will be included in the legal system and get protection of the rights and interests.

\subsection{Administrative Supervision System}

The main body of the administrative supervision system is the relevant government departments. This department supervise the implementation of policies and regulations, the entire construction process and the market behavior of the participants in the regulation, to promote the construction and development of the elderly living facilities.

\section{Countermeasures and suggestions}

\subsection{Improve Relevant Policies and Regulations}

Through the analysis of the experience of the developed countries, the policies and regulations play a vital role in the development process. We should accelerate the improvement of policies and regulations to support the construction of pension facilities, establish a scientific system of legal operation mechanism. Specific include: in-depth design standards and appropriate aging transformation of elderly residential, residential security. The old performance; the provisions of the new residential and ancillary facilities for the elderly is inside the house to make quantity, etc.

\subsection{Increase Financial Support}

First of all, the government should increase funding for the cause of the pension, to provide a certain amount of subsidies for the needs of the transformation of residential users, providing tax benefits for community developers, financing preferential policies. In addition, because of the pension business of high input and low output, not for profit, it is impossible to rely on the government investment entirely. 
We should mobilize social forces to actively participate in investment, accelerate to encourage private capital to participate in the construction of facilities for the elderly.

\subsection{Pay Attention to the Training of Relevant Personnel}

The construction of China's pension facilities is still in its infancy.as the development of aging, the development and operation of the pension community needs a large number of related professionals. Faced with the serious shortage of professionals, we must speed up the pace of training related professionals, set up related courses in some colleges and universities. At the same time, we are engaged in continuing education of the staff in this field, training their professional skills and improving their professional level.

\section{Conclusion}

Based on the practical experience of the developed countries in the process of the construction of pension service facilities, combined with the development of China's current situation, the pension facilities development system has been established. The application of research results will help to improve the living conditions of the elderly and improve the life quality of the elderly.

\section{References}

[1]. Tong xing. The development of community home care services to deal with the aging [J]. Exploration and contend, 2015, 08:69-72.

[2]. He Linghua, Wei Gang. The problems and Countermeasures of the aging of the outdoor environment of the community [J]. Planner, 2015, 11:23-28.

[3]. Yang Zhihao. Pension real estate financing and profit model [J]. China real estate market, 2012, 03:66-67. 